\title{
Stereoscopic Micro PIV Investigation of Velocity Boundary Layer Near Piston Top of a Tumble Enhanced SI IC Engine
}

\author{
M. Shimura ${ }^{1 *}$, E. Yokoyama ${ }^{1}$, H. Kosuda ${ }^{1}$, M. Kamata ${ }^{2}$, O. Nakabeppu ${ }^{2}$, \\ T. Yokomori ${ }^{3}$, M. Tanahashi ${ }^{1}$ \\ ${ }^{1}$ Tokyo Institute of Technology, Department of Mechanical Engineering, Tokyo, Japan \\ ${ }^{2}$ Meiji University, Graduate School of Science and Technology, Kanagawa, Japan \\ ${ }^{3}$ Keio University, Graduate School of Science and Technology, Kanagawa, Japan \\ *shimura.m.aa@m.titech.ac.jp
}

\begin{abstract}
To develop higher efficiency and lower emission gasoline engines, ultra-lean burning under high Reynolds number conditions is desired. It is believed that enhancement of tumble flow in the engine cylinder is effective for increase of turbulent intensity, resulting in improvement of characteristics of flame propagation and ignition under a strong discharge, while the enhancement of tumble flow might cause heat loss from the wall. Investigations of characteristics of turbulence and distributions of wall and gas temperature in engine cylinders are still challenging due to transient and high pressure, and due to cycle-to-cycle variations. In the previous study (Jainski et al., 2013), a micro particle image velocimetry (micro PIV) measurements were conducted in an engine cylinder at up to $1100 \mathrm{rpm}$ and the characteristics of velocity boundary layer around a cylinder head were investigated. The study has shown that the log-law does not properly present the measured velocity distributions near the wall. In our previous study (Shimura et al., 2018), a micro PIV was conducted in a motored engine cylinder to investigate velocity boundary layer characteristics near piston top before the top dead center (TDC) at a constant engine speed of $2000 \mathrm{rpm}$ to deepen understanding characteristics of velocity boundary layer in engine cylinder with tumble flow. The velocity boundary layer was well fitted to the Blasius theory at $30 \mathrm{CAD}$ before TDC and deviated from the theory at $15 \mathrm{CAD}$ before TDC. However, the obtained data was two components of velocity in the measurement plane, which means that effects of magnitude of velocity were not clear in the previous measurement. In this study, stereoscopic micro PIV was conducted to elucidate the effects of magnitude and direction of velocity on the characteristics of velocity boundary layer near the piston top in the tumble enhanced SI IC optical engine.

The tumble enhanced SI IC optical engine used in the previous study (Shimura et al., 2018; Matsuda et al., 2019) was used also in this study. The bore is $75 \mathrm{~mm}$ and the stroke is $112.5 \mathrm{~mm}$. Length of the connecting rod is $250 \mathrm{~mm}$. The engine has two intake valves of the diameter $29 \mathrm{~mm}$ and two exhaust valves of the diameter $25 \mathrm{~mm}$. The compression ratio is 13.0. The optical access is achieved through the quartz glass cylinder. A tumble enhancing intake port is used for the sake of improvement of ignition and flame propagation. The engine speed can be set up to $2000 \mathrm{rpm}$ at the maximum. The overall flow fields taken by a preliminary PIV experiment can be seen in the literatures (Shimura et al., 2018; Matsuda et al., 2019).

The laser beams for PIV are from two Nd:YAG lasers (LOTIS, LS-2131, $150 \mathrm{~mJ} / \mathrm{pulse}, 532 \mathrm{~nm}$ ) are led to the same optical axis by a mirror and a polarizing beam splitter. The laser beam is formed into laser sheet of $180 \mu \mathrm{m}$ thickness by laser sheet forming optics and led into the engine cylinder. The scattering light was collected by long distance microscope lenses (Quester, SZM100) and imaged onto CCD cameras (Princeton Technology, ES4020) in the stereoscopic alignment with 18 degrees. To compensate for the difference in the focal length caused by the quartz engine liner, a cylindrical lens of $1000 \mathrm{~mm}$ focal length was placed in front of each long distance microscope lens. $\mathrm{SiO}_{2}$ of $1 \mu \mathrm{m}$ mean diameter was used for tracer particles. The micro PIV was operated at about $6.6 \mathrm{~Hz}$ to be synchronized with engine speed. The time separation of the successive particle images was $1.5 \mu \mathrm{s}$.

The field of view of the micro PIV was $3.5 \mathrm{~mm} \times 3.5 \mathrm{~mm}$ on the piston top including central axis of the cylinder. Here, $x$ and $y$ coordinates are set to the direction from the exhaust to the intake valves and the
\end{abstract}


direction from the piston to the pent roof, respectively. $z$ coordinates is perpendicular to $x$ and $y$ axes, and the orizin of the coordinates is set at the center of the piston top. The spatial resolution of PIV, which is defined by the size of interrogation region, is $108.8 \mu \mathrm{m} \times 54.4 \mu \mathrm{m}$. Vector spacing is $54.4 \mu \mathrm{m} \times 27.2 \mu \mathrm{m}$. The first vector position is about $27.2 \mu \mathrm{m}$ away from the wall. The measurements were conducted at 345 CAD. The engine was motored at $2000 \mathrm{rpm}$ and operated for three intake valve open timings of -30 CAD.

The operation condition of the engine tested contain strong cycle-to-cycle variations, which results in the large root-mean-square values of velocity fluctuation near the center of the piston top (Shimura et al., 2018). To evaluate flow characteristics in the cycle-to-cycle variations, conditional averaging based on magnitude of fluid velocity is used in this study. Figure 1 a) shows a histogram of the magnitude of combined velocity of $u$ and $w$. The magnitude of velocity can be considered as momentum of fluid because few fluctuation of density is considered and temperature boundary layer is enough thin compared to the velocity boundary layer. The large variations in the momentum can be observed in Fig. 11(a). The large variations are considered to be caused by the variations of tumble core locations. The fraction of the large momentum Here, the momentum are classified into $\mathrm{C} 1$ to $\mathrm{C} 4$ based on fractions $(\mathrm{C} 1: 54.4 \%, \mathrm{C} 2: 19.5 \%, \mathrm{C} 3: 19.5 \%, \mathrm{C} 4: 6.6 \%)$. Figure 1 (b) and (c) shows mean velocity distribution classified into $\mathrm{C} 1$ and $\mathrm{C} 4$ in Fig. 11(a). The distribution is fitted to the log-law velocity profile of developed wall turbulence. The mean velocity profile for $\mathrm{C} 1$ shows large discrepancy from that of general turbulent boundary layers, while that for $\mathrm{C} 4$ show relatively close to that of general turbulent boundary layer. $\mathrm{C} 2$ and $\mathrm{C} 3$, which are not shown here, have trend between the $\mathrm{C} 1$ and $\mathrm{C} 4$ profiles. These results show that the velocity profiles which can be assumed to be the developed turbulent boudary layer in the targeted condition is less than half of cycles, which means partial applicability of conventional CFD models for prediction of boundary layer of the engine condition.

\section{Acknowledgements}

This work is the result of a collaborative research program with the Research association of Automotive Internal Combustion Engines (AICE) for fiscal year 2020. The authors gratefully acknowledge the concerned personnel.

\section{References}

Jainski C, Lu L, Dreizler A, and Sick V (2013) High-speed micro particle image velocimetry studies of boundary-layer flows in a direct-injection engine. International Journal of Engine Research 14:247-259

Matsuda M, Yokomori T, Minamoto Y, Shimura M, Tanahashi M, and Iida N (2019) A Cycle-to-Cycle Variation Extraction Method for Flow Field Analysis in SI IC Engines Based on Turbulence Scales. in SAE Technical Papers. January

Shimura M, Yoshida S, Osawa K, Minamoto Y, Yokomori T, Iwamoto K, Tanahashi M, and Kosaka H (2018) Micro particle image velocimetry investigation of near-wall behaviors of tumble enhanced flow in an internal combustion engine. International Journal of Engine Research page 1468087418774710
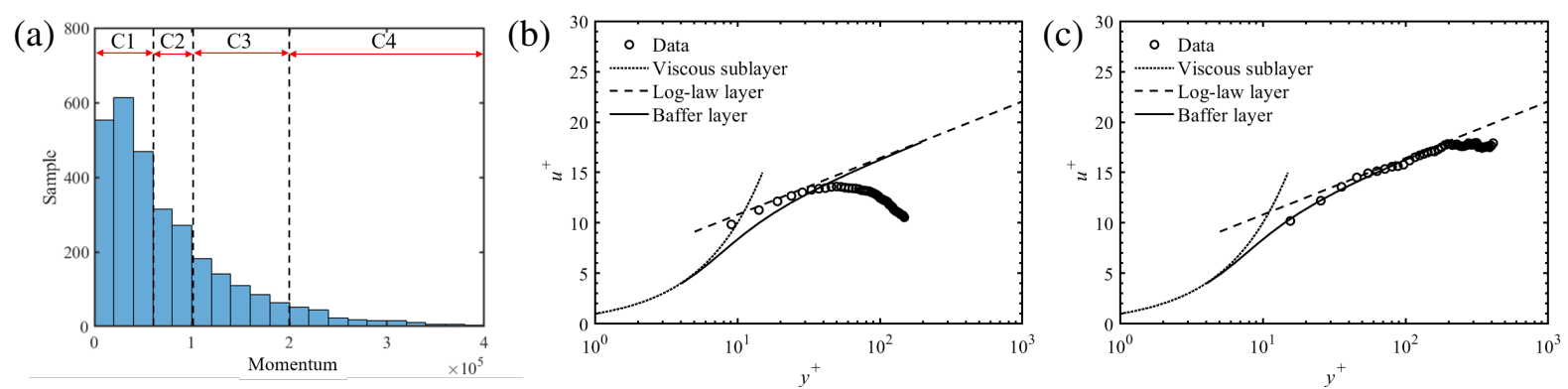

Figure 1: (a) Histogram of momentum. Mean velocity distribution classified based on the magnitude of momentum for (b) $\mathrm{C} 1$, (c) $\mathrm{C} 4$ in the histrgram. 